\title{
Cartografiando Experiencias al Interior de la Escuela Rural: Profesores de Matemática y el Dispositivo Evaluación
}

\author{
Carolina Tamayo ${ }^{1}$ \\ Derly Johana Martínez Oviedo ${ }^{2}$ \\ Jáder Sneider Serna Martínez. \\ Julián Andrés Arrubla Osorio ${ }^{4}$
}

\begin{abstract}
RESUMEN
Este artículo tiene como objetivo presentar el problema de investigación, el horizonte conceptual, la ruta metodológica, algunos resultados de una investigación de maestría en desarrollo. Esta investigación tiene como objetivo (re)significar la evaluación en cuanto dispositivo presente en el currículo escolar de Matemática con profesores de tres Instituciones Educativas Rurales del Suroeste Antioqueño (Colombia). Con base en los trabajos de Michel Foucault y las teorías post-estructuralistas del currículo, buscamos cartografiar las experiencias vividas al interior de dichas instituciones, problematizando con profesores la evaluación en cuanto dispositivo de control presente en el currículo escolar de Matemática. Con esta experiencia hemos venido construyendo caminos junto a los profesores entorno al objeto de estudio, como proceso de constante reflexión sobre la escuela rural. Es así como la evaluación puede ser vista como proceso constante en el cual intervienen diferentes culturas, permitiendo el trabajo en grupo y experiencias investigativas en el aula.
\end{abstract}

\footnotetext{
${ }^{1}$ Doctora en Educación por la Universidad Estadual de Campinas. Profesora de la Facultad de Educación de la Universidade Federal de Minas Gerais (Belo Horizonte, Brasil). Profesora colaboradora del programa de Posgraduación en Educación de la Universidad de Antioquia (Medellín, Colombia). https://orcid.org/0000-0002-8478-7845. carolina.tamayo36@gmail.com.

${ }^{2}$ Estudiante de Maestría en Educación. Universidad de Antioquia, Medellín, Colombia. https://orcid.org/0000-00034742-7311.derly.martinezo@udea.edu.co.

${ }^{3}$ Estudiante de Maestría en Educación. Universidad de Antioquia, Medellín, Colombia. https://orcid.org/0000-00021913-2885.jader.serna@udea.edu.co.

${ }^{4}$ Estudiante de Maestría en Educación. Universidad de Antioquia, Medellín, Colombia. https://orcid.org/0000-00032129-5672.julian.arrubla1@udea.edu.co.
} 
PALABRAS CLAVE: Currículo. Dispositivo. Educación Matemática. Ruralidad.

Cartographe of Experiences Inside the Rural School: Mathematics Teachers and Evaluation Apparatus

\begin{abstract}
This article aims to present the research problem, the conceptual horizon, the methodological route, and some results of a master's research in development. This research aims to (re)mean the evaluation as a device present in the Mathematic school curriculum with teachers from three rural educational institutions of the southwest Antioquia (Colombia). Based on the works of Michel Foucault and the poststructuralist theories of the curriculum, we seek to mapping the experiences that we lived whit these teachers when the evaluation is problematizing as a control device present in the Mathematic school curriculum. With this experience we have been building paths with teachers around the object of study, as a process of constant reflection on the rural school. This is how evaluation can be seen as a constant process in which different cultures intervene, allowing group work and research experiences in the classroom.
\end{abstract}

KEY-WORDS: Curriculum. Device. Mathematics Education. Rurality.

\title{
Introducción
}

Desde el 2002 en Colombia el Ministerio de Educación Nacional (MEN) ha venido impulsando el desarrollo del 'Proyecto de Educación Rural' (PER), el cual ha buscado "mitigar los problemas que afectan la cobertura y la calidad educativa en zonas rurales, ayudando a superar la brecha existente entre la educación rural y urbana"5. Para lo anterior, se han implementado en el país modelos educativos flexibles - con el apoyo del Gobierno Central y del Banco Mundial - con base en materiales y metodologías que buscan el reemplazo de

\footnotetext{
${ }^{5}$ Tomado de: https://www.mineducacion.gov.co/1759/w3-article-329722.html?_noredirect=1.
} 
los modelos de educación tradicional diseñados para estudiantes que viven en contextos urbanos.

La implementación de este proyecto nacional, sin duda alguna, ha mejorado la cobertura, sin embargo, como informa el MEN "la tasa de cobertura en las áreas rurales es de 30\% comparada con 65\% de las urbanas, y la tasa de deserción a nivel rural es de 10.9\%, mientras en las ciudades ésta es de $2.5 \%$. La participación en los programas de preescolar es de menos de $4 \%$ en las zonas rurales"6. Adicionalmente "si tenemos en cuenta que uno de cada cuatro colombianos, forma parte de la población rural y que, el $44 \%$ de ésta, se encuentra en situación de pobreza multidimensional"7 podríamos entender, en parte, porque en la educación rural del país existe un alto índice de deserción escolar de los niños, niñas y jóvenes.

Por otro lado, a pesar de la promoción del MEN de diversos modelos educativos flexibles para las instituciones rurales - que buscan ser más apropiados para la vida en el campo - se continúan promoviendo los mismos contenidos matemáticos para los currículos escolares rurales y, también, las mismas prácticas evaluativas estandarizadas (como las pruebas SABER 8 nacionales), lo que ha contribuido para mantener y perpetuar las brechas de exclusión existentes entre los pobladores rurales y urbanos.

Reconociendo la persistencia de estos problemas de acceso, permanencia y pertinencia, y con base en diferentes experiencias vividas como profesores, nace este proyecto de investigación que, desde y para tres Instituciones Educativas Rurales de carácter oficial ${ }^{9}$ pretende problematizar la evaluación en cuanto dispositivo presente en el currículo escolar de Matemática $^{10}$, en pro de promover otros caminos desde la Educación

\footnotetext{
${ }^{6}$ Tomado de: $\underline{\text { https://www.mineducacion.gov.co/1621/article-87159.html }}$

${ }^{7}$ Tomado de: https://www.elespectador.com/colombia2020/territorio/la-dificil-situacion-de-las-escuelas-rurales-encolombia-articulo-856698

${ }^{8}$ Según Ministerio de Educación Nacional de Colombia - MEN - (2018), son evaluaciones periódicas que se realizan para medir las competencias de los estudiantes. Tomado de: https://www.mineducacion.gov.co/1759/w3-article244735.html

${ }^{9}$ Ubicadas en la subregión del Suroeste del departamento de Antioquia (Colombia).

${ }^{10}$ En esta investigación diferenciamos entre Matemática con ' $\mathrm{M}$ ' mayúscula y matemáticas en plural de la siguiente manera: La primera la comprendemos en el sentido de Emanuel Lizcano (2002), quien se refiere a ella como el conocimiento Matemático propio de la cultura occidental y, la segunda, en el sentido de Tamayo-Osorio (2016) quien
} 
Matemática para la disminución de estas brechas educativas.

Vale la pena notar que las instituciones en las que estamos realizando la investigación son: el Centro Educativo Rural Urbano Ruíz (CERUR) ${ }^{11}$, el Centro Educativo Rural Peñalisa (CERP) ${ }^{12}$ y la Institución Educativa Orlando Velásquez Arango (IEOVA) ${ }^{13}$ (Ver figura 1).

FIGURA 1: Localización territorial de las instituciones educativas.

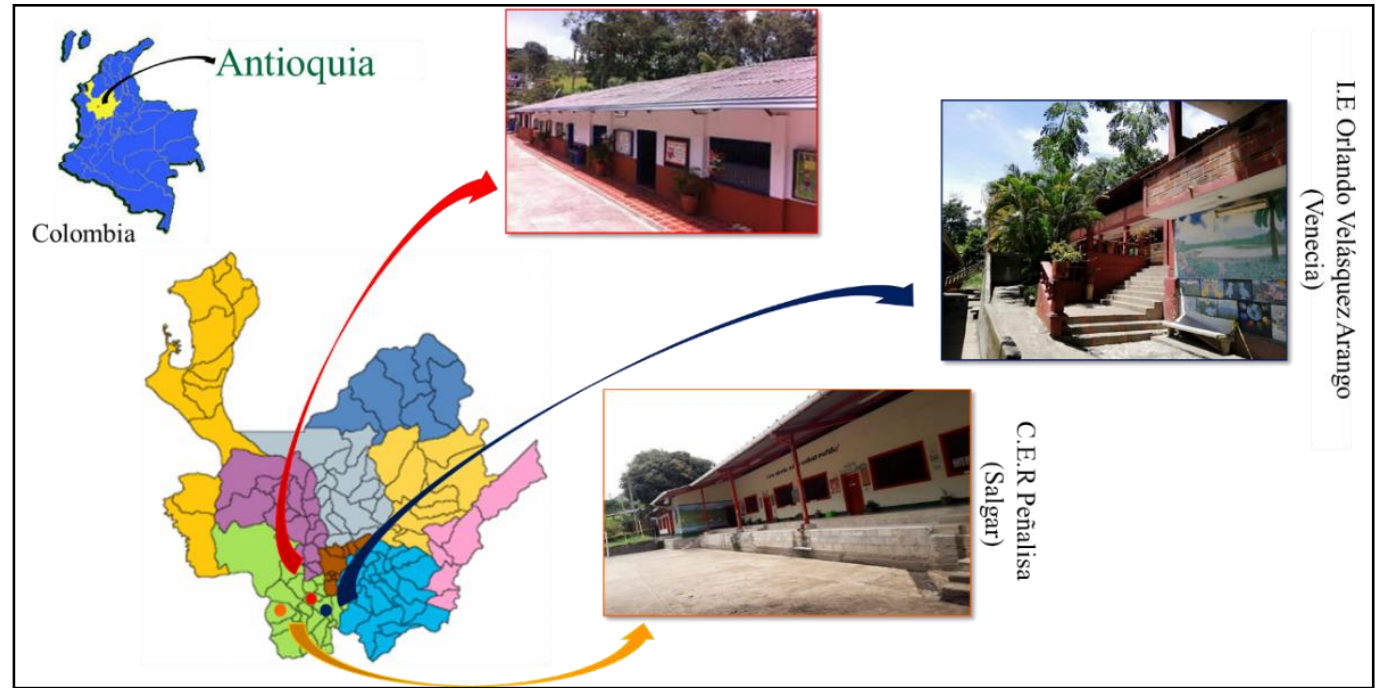

Fuente: elaboración propia de los investigadores (2019).

Teóricamente nos aproximaos a los pensamientos de Michel Foucault (1968; 1999; 2009) en el campo de la filosofía, así como, de Clareto (2013), Jaramillo (2011), Knijnik (2014), Monteiro \& Mendes (2011), Tamayo-Osorio (2016), Veiga-Neto (2008; 2013), Zanlorenzi (2017), Sánchez-Amaya (2009; 2013), Quiceno \& Peñalosa (2014) y Walker \& Tamayo-Osorio (2018), en el área de la educación. También centramos nuestra mirada en los análisis desarrollados por Silva $(1995 ; 1999)$ referentes al campo de los estudios del currículo, y, retomamos diferentes investigaciones de la Educación Matemática que ya han trabajado con la cartografía como actitud metódica para investigar (AMARIS, 2013; AMORIM, 2010) con base en las

la retoma como la producción de conocimientos y su significado desde y para las prácticas sociales con base en estudios de la filosofía.

${ }^{11}$ Ubicada en el corregimiento de Camilo C, Municipio de Amagá.

${ }^{12}$ Ubicado en el corregimiento de Peñalisa, Municipio de Salgar.

${ }^{13}$ Ubicada en el corregimiento de Bolombolo, Municipio de Venecia. 
investigaciones realizadas por Rolnik (1989), Deleuze \& Guattari (2004) y Passos, Kastrup \& Escóssia (2015).

\section{Problema de investigación}

Como fue señalado anteriormente, tomamos como punto de partida algunas experiencias vividas como profesores de Instituciones Educativas Rurales -IEOVA, CERUR y CERP- que nos llevaron a investigar sobre el dispositivo evaluación presente en el currículo escolar de Matemática. El siguiente episodio lo vivimos en una de las Instituciones Rurales y nos permitió identificar la importancia de abrir este debate desde la ruralidad:

Durante una jornada pedagógica, planeada, organizada y desarrollada por los directivos docentes, uno de los profesores que imparte el área de matemáticas en la básica secundaria, manifiesta estar inconforme con la mesa de trabajo del área, por no tener $100 \%$ estructurada la malla curricular para el grado que él tiene a cargo. Así, el docente exige que dicha reforma y estructura esté acorde a la reglamentación vigente, para poder ceñirse y orientar debidamente sus clases. Además, argumenta que esta es la carta de navegación para que se hable un mismo idioma en la institución y de esta manera poder mejorar los resultados en las pruebas de estado ${ }^{14}$ para los grados $3^{\circ}, 5^{\circ}, 9^{\circ}$ y $11^{\circ}$, ya que la institución desde tiempos atrás se encuentra en desempeño inferior. Por otro lado, reitera que se conserve la intensidad horaria según lo estipulado por el consejo académico, los exámenes tipo prueba saber al finalizar cada periodo y el control cuantitativo de los resultados de los estudiantes en el área, el cual se distribuye: 50\% seguimiento, 20\% examen de periodo, $20 \%$ actividad evaluativa, $5 \%$ autoevaluación y 5\% coevaluación. En la misma reunión se presenta un debate al respecto del orden de las clases a cargo de uno de los directivos,

${ }^{14}$ Examen que se realiza en el aula, tomando como base las pruebas SABER $3^{\circ}, 5^{\circ}, 9^{\circ}$ y $11^{\circ}$. 
enunciando que es pertinente domesticar a los estudiantes, disciplinarlos en su espacio habitual y siempre tenerlos en orden al interior de las aulas, con el fin de estar siempre en sintonía con lo que demanda la normatividad, recordando que esos sujetos son el producto que saca anualmente la institución desde el conocimiento que se imparte en cada una de las áreas, en especial Matemática, español, sociales, ciencias e inglés. Por otro lado, se debe planificar bien las clases, registrarlas y respetar los tiempos como parte del servicio que se presta a la comunidad ${ }^{15}$. (itálico nuestro)

Enunciaciones como "mejorar resultados en las pruebas del estado", "desempeño inferior", "examen tipo prueba saber", "control cuantitativo de los resultados de los estudiantes", "normatividad", "producto", "planificar bien las clases, registrarlas y respetar los tiempos" y “domesticar a los estudiantes", están vinculadas a las prácticas examinadoras escolares que nos muestran cómo la evaluación es útil para clasificar quien avanza o no, etiquetar, preparar, señalar, estandarizar, vigilar, controlar, lo cual hace de cada sujeto un caso (FOUCAULT, 2009), operando como una "herramienta para la homogeneización: para la vigilancia de individuos, de las instituciones, de las poblaciones; para su regulación, su gestión, su normalización, su objetivación, su control, su dominio" (SÁNCHEZ-AMAYA, 2013, p. 755).

Así, en las tres Instituciones Educativas Rurales comenzamos a evidenciar, desde nuestras prácticas pedagógicas, y en el diálogo con nuestros colegas, que las prácticas examinadoras en la escuela rural nos han permitido durante siglos determinar diferencias entre lo bueno y lo malo, lo aceptado y lo rechazado, y han sustentado "una escuela examinadora, que más que examinar, trabaja en la constitución de subjetividades y en la invención de un mundo, cuyo parámetro es la competencia, una sociedad inscrita en la lógica evaluativa” (RESENDE, 2015, p. 287).

El episodio nos coloca frente a la importancia de reflexionar y

\footnotetext{
${ }^{15}$ Situación narrada por los investigadores.
} 
(re)significar la evaluación en el contexto de la Educación Rural, ya que ha sido pautada en términos de detectar qué tanto han aprendido los "estudiantes homogeneizados, unificados, normalizados, regularizados [...], sometidos a las mismas prácticas evaluativas, desconociendo, en todo caso, circunstancias, intereses, necesidades, expectativas y objetivos individuales" (SÁNCHEZ-AMAYA, 2013, p. 761).

Concebir la evaluación en cuanto dispositivo significa entender cómo está se vincula con las formas de disciplinarización escolar en las que "según Foucault, saber y poder se encuentran mutuamente implicados" (SILVA, 1995, p. 5), determinando cómo los cuerpos y saberes escolarizados se han venido definiendo en pro de la sociedad moderna.

La construcción de currículos disciplinariamente organizados da cuenta de esa indisociabilidad entre saber/poder al estar influenciados y construidos por los discursos de diversos segmentos de la sociedad (imbricados en relaciones de poder), que consolidan, por ejemplo, que el conocimiento Matemático es uno de los más importantes a ser enseñados en la escuela, al mismo tiempo que, se excluyen otros conocimientos. Muchos de estos discursos están vinculados con un deseo de homogenización de los sujetos de la educación (sea alumnos, profesores, directivos, entre otros) y donde la disciplina juega un papel fundamental para:

[...] encauzar la conducta del sujeto, y en el marco de la institución escolar esto implica que el alumno deberá ir dejando de lado de su naturaleza la pereza, la impuntualidad, la desobediencia o la indisciplina, para dar lugar a un sujeto obediente, dócil, responsable, puntual y productivo. (QUIROGA, 2017, p. 226).

Buscando encauzar la conducta de los sujetos de la educación, la escuela se vale de mecanismos y técnicas para estructurar, jerarquizar y fragmentar los saberes, uno de ellos es el currículo escolar, otro puede ser la aplicación de evaluaciones estandarizadas a grande escala (pruebas SABER 
$3^{\circ}, 5^{\circ}, 9^{\circ}$ y $11^{\circ}$ en el caso colombiano) que, además, sirven para clasificar los estudiantes según su 'capacidad' de aprendizaje. Así, "el poder de la escuela radica en buena medida en sus propios dispositivos de poder/saber, sus métodos disciplinarios, sancionadores, de instrucción o correctores (con sutiles diferencias entre todos ellos)" (MORAL, 2008, p.73), aspectos que se vinculan al currículo en general.

Con base en lo anterior surgió la siguiente pregunta de investigación: ¿cómo los profesores de tres Instituciones Educativas Rurales del Suroeste Antioqueño (re)significan la evaluación en cuanto dispositivo presente en el currículo escolar de Matemática?, y, en coherencia nuestro objetivo es (re)significar la evaluación en cuanto dispositivo presente en el currículo escolar de Matemática con profesores de tres Instituciones Educativas Rurales del Suroeste Antioqueño.

\section{Horizonte conceptual de la investigación}

Para el desarrollo de esta investigación hemos estudiado conceptos como evaluación, currículo escolar en Educación Matemática, dispositivo y Educación Rural, y pretendemos presentarlos a continuación de forma teórica con el objetivo de localizar el lugar desde donde hablamos.

En la perspectiva de las teorías del currículo Silva $(1995 ; 1999)$ plantea tres posturas: teorías tradicionales, teorías críticas y finalmente, las teorías pos-críticas. Esta última, desde la cual estamos desarrollando este proyecto de investigación, pretende ir más allá de las estructuras controladoras y espacios cerrados de la enseñanza al cuestionar no solo lo propuesto por las teorías críticas, sino también: ¿Cómo debe ser visto el sujeto? ¿Qué importancia tiene el sujeto en el currículo y la sociedad? ¿Qué subjetividades se pretenden construir?, esta teoría centra su mirada en la pregunta ¿A quién enseñamos?.

La postura de las teorías pos-críticas no solo se remiten a la crítica del tecnicismo impuesto por la modernidad para el trabajo sistemático y cognitivo 
en la escuela, sino que también, busca pensar el currículo como algo que va más allá de la fabricación de sujetos, puesto que involucra historias, creencias, actos, sentimientos, culturas, subjetividades, relaciones sociales y de poder, construcciones colectivas y epistemológicas del conocimiento.

Ver el currículo de Matemática desde esta perspectiva nos permite problematizarlo en tanto una forma de control-producción, en el cual participan un entramado de dispositivos que a su vez están presentes en la institución escolar; mecanismos que encausan las formas de sujeción de sujetos favoreciendo la formación de cuerpos dóciles, homogéneos y estandarizados.

La evaluación como parte del currículo de Matemática puede ser comprendida como uno de esos dispositivos de control, lo cual ha sido señalado por Sánchez-Amaya (2009; 2013), Wanderer \& Knijnik (2014) y Quiceno \& Peñaloza (2014) con base en el pensamiento de Michel Foucault.

Así, los dispositivos son una manifestación de una red de poder/saber en la cual según Foucault (2009) el discurso ${ }^{16}$ juega un papel importante, ya que, los corporiza debido a que "son modalidades según las cuales se ejerce el poder" (p.153). Por tanto, los dispositivos pueden ser comprendidos como un conjunto de acciones y discursos que se llevan a cabo mediante técnicas de disciplinarización, buscando el control del cuerpo y del saber.

En palabras de Agamben (2011) dispositivo puede ser comprendido, con base en el pensamiento de Michel Foucault, como "[...] un conjunto de praxis, de saberes, de medidas y de instituciones cuya meta es gestionar, gobernar, controlar y orientar - en un sentido que se quiere útil - los comportamientos, los gestos y los pensamientos de los hombres" (p. 256).

Los dispositivos contribuyen para capturar a los sujetos, moldeándolos, controlándolos, orientándolos a conductas determinadas, "de esta manera, el dispositivo, antes que todo, es una máquina que produce subjetivaciones y,

\footnotetext{
${ }^{16}$ Según Veyne (2008) este es interpretado como "una práctica discursiva" la cual "consistirá en interpretar lo que la gente hacia o decía, comprender lo que suponen sus gestos, palabras, instituciones, cosa que hacemos a cada minuto: nosotros nos comprendemos entre nosotros." (p. 23).
} 
por ello, también es una máquina de gobierno” (AGAMBEN, 2011, p. 261).

En este sentido la evaluación como mecanismo de control presente en el currículo escolar de Matemática y en la escuela, produce subjetivaciones y puede ser entendida como un dispositivo que, mediante el uso de técnicas, vuelve a los sujetos de la educación manipulables, prescritos, normalizados, regulados, obedientes, clasificados, certificados, validados, ratificados y castigados; es decir, "el dispositivo evaluación descubre, revela, describe [...], completamente a los individuos, los expone ante su propia desnudez; exhibe al sujeto" (SÁNCHEZ-AMAYA, 2013, p. 759).

A su vez las técnicas presentes en la evaluación, las comprendemos como el conjunto de métodos que permiten la dominación y vigilancia constante de los cuerpos para hacerlos dóciles y maleables, como es expresado por Foucault (2009) al referirse a ese concepto como:

Pequeños ardides dotados de un gran poder de difusión, acondicionamientos sutiles, de apariencia inocente, pero en extremo sospechosos, dispositivos que obedecen a inconfesables economías, o que persiguen coerciones sin grandeza, son ellos, sin embargo, los que han provocado la mutación del régimen punitivo [...] (p.161).

Las técnicas están presentes en lo que Foucault (2009) categorizó como el arte de las distribuciones y el control de la actividad de las instituciones, como se ejerce en la escuela.

Algunas de estas técnicas se basan en la organización de los individuos en los espacios, buscando la consolidación de "espacios complejos: arquitectónicos, funcionales y jerárquicos al mismo tiempo. Son espacios que establecen la fijación y permiten la circulación” (FOUCAULT, 2009, p.171), posibilitando la evaluación de los sujetos encausados. Estas son llamadas de técnicas del buen encausamiento temporo-espaciales: la clausura, las divisiones de zonas, los emplazamientos funcionales y el rango (FOUCAULT, 2009). 
Otras técnicas, en palabras de Morales \& Veiga-Neto (2008, p. 4), están centradas en la "capitalización del tiempo y control de actividades", ellas actúan para encausar el cuerpo y el saber de los sujetos, estas son: el empleo del tiempo, la elaboración temporal del acto, la correlación del cuerpo y el gesto, la articulación cuerpo-objeto, la utilización exhaustiva y los medios de buen encausamiento: la jerarquía y la sanción (FOUCAULT, 2009). Técnicas presentes en las prácticas examinadoras.

Todas estas técnicas son utilizadas en la evaluación constituyéndola un dispositivo de control, ya que valiéndose de ellas busca homogeneizar, monitorear, estandarizar, ratificar, validar y sistematizar. Así, problematizar la evaluación en el currículo escolar de Matemática significa comprender que ella ha actuado como un dispositivo que no solo examina y mide cuánto se aprende, si no, que también, regula qué se aprende, clasifica a los sujetos y registra la validez del proceso educativo, entre otras cosas.

Prácticas como examinar, controlar, vigilar, estandarizar, reproducir, sistematizar, analizar, aprobar, diseñar, entre otras, son determinantes en las formas de conducción del profesor, del estudiante, de los directivos y de los padres con respecto al currículo escolar de Matemática, debido a que "en lo que se refiere específicamente al trabajo con las matemáticas, es posible afirmar que las técnicas utilizadas para que los estudiantes desarrollen la capacidad de calcular pueden actuar como elemento disciplinador, pues instituyen una racionalidad específica para su realización" (ZANLORENZÍ, 2017, p. 289).

De este modo, consideramos que realizar una problematización de la evaluación en cuanto dispositivo, presente en el currículo escolar de Matemática, en el ámbito de las escuelas rurales, es fundamental para: repensarla, reflexionarla, analizarla y finalmente (re)significarla, en el sentido de que la problematización en palabras de Foucault (1999):

[...] es el conjunto de prácticas discursivas o no discursivas que hace que algo entre en el juego de lo verdadero y de lo falso y lo constituye 
como objeto para el pensamiento (bien sea en la forma de la reflexión moral, del conocimiento científico, del análisis político, etc.) (p.23).

Así, el problematizar la evaluación con profesores de Matemática, no solo permitirá comprender cómo está se ha constituido como un dispositivo de control presente en la escuela rural, sino que también, nos permitirá interactuar con sus medios de producción y "entender el orden de la misma, es decir, de la elaboración de un dominio de hechos, de prácticas y de pensamientos que plantean problemas" (FOUCAULT, 1999, p. 56).

Con base en lo anterior, partimos de las voces de los profesores de Matemática de las escuelas, de sus prácticas pedagógicas, como sujetos que están inmersos en la vida de la escuela rural que reclaman su participación en los debates que involucran su práctica. De este modo, nuestra investigación parte del escuchar y problematizar con estos profesores la evaluación, y cómo está se ha asumido al interior del currículo escolar de Matemática que tiene como referencia una concepción de Matemática como un conocimiento único, neutro y universal.

Es importante resaltar que la Educación Rural ha sido objeto de estudio de investigadores como Arias (2017), Abós \& Boix (2017), Boix (2003; 2011; 2014), Glavam \& Soarez (2017), Núñez (2004) y Valencia (2015), quienes ya han planteado la urgencia de que sean cuestionados los currículos educativos homogeneizados promovidos por el estado, así como, la evaluación estandarizada, toda vez que, imponen como único conocimiento valido los saberes occidentales, generando lo que Boix (2003) ha denomino desruralización.

En este sentido, cuando pensamos en las escuelas de la ruralidad vemos que es importante reflexionar sobre: ¿Qué hace particulares a dichas instituciones? ¿Qué conocimientos culturales prevalecen en dichos espacios rurales? ¿Qué conocimientos deben ser fortalecidos según la necesidad del contexto? y ¿Cómo reflexionar la evaluación, según las prácticas que allí se 
hacen comunes y fundamentales?, esto se debe a que dichos espacios según Boix (2003),

[...] se caracteriza justamente porque tiene identidad propia. Sus habitantes forman parte de un colectivo social con códigos culturales concretos, léxicos y símbolos característicos, costumbres diferentes (gastronomía, artesanía, agroturismo, experiencias musicales, etc.) y comportamientos basados en las interacciones multifacéticas de sus miembros. (p. 4).

Es por esto, que los espacios o contextos rurales, son característicos por estar fuera de lo que se cataloga como urbano o metrópoli, pero no sesgando lo rural al trabajo del agro, de lugares alejados de la civilización y de la relación directa con la tierra y el campo, puesto que, la ruralidad implica la convergencia entre costumbres, sujetos, acciones, acontecimientos, progresos y transformaciones, es decir:

La ruralidad en esta era de las comunicaciones y los mercados globales pasó de ser territorios definidos por el uso exclusivo de actividades primarias de la agricultura y la ganadería para convertirse en espacios dinámicos e interconectados en el que coexisten las actividades primarias, las agroindustrias y los usos residenciales y de esparcimiento (NÚÑEZ, 2004, p. 2).

A su vez, las practicas sociales, las identidades culturales, los problemas de comunidad, las prácticas de los campesinos, la diversidad e intereses poblacionales hacen que la concepción tradicional de la ruralidad se haya ido transformando, cuestionando sus necesidades, para darle solución a problemáticas comunitarias con aquellas herramientas y habilidades que saben y poseen, ya que conservan un saber cultural (ARIAS, 2017).

Es a partir de lo anterior, que, en nuestra investigación, se aborda la Educación Rural, pensando en el fortalecimiento de las relaciones sociales y 
los conocimientos culturales propios de los espacios territoriales en los que se localizan las instituciones, determinantes en la constitución de las subjetividades, al "asumir lo rural más allá de un espacio geográfico como un espacio construido históricamente, habitado por unos sujetos con una cultura particular" (VALENCIA, 2015, p. 33).

\section{El camino metodológico de la investigación}

La investigación cuenta con la participación de algunos profesores que enseñan Matemática en las Instituciones Educativas Rurales anteriormente mencionadas -IEOVA, CERUR y CERP-; destacando que nosotros como investigadores somos profesores activos en esos espacios escolares.

Para ello hemos realizado de forma independiente en cada institución encuentros grupales e individuales durante el segundo semestre del 2019; los encuentros individuales se desarrollaron en diferentes sesiones con algunos docentes, basados en entrevistas y diálogos, en los cuales se efectuaron grabaciones para llevar registro de las experiencias narradas y las concepciones sobre la evaluación dentro de la escuela rural.

Los encuentros grupales se realizaron en sesiones que fueron desarrolladas al interior de un "Grupo de Estudio sobre la Evaluación en Educación Matemática" (GESEEM), conformado en cada una de las Instituciones Educativas Rurales para reflexionar sobre aquellas experiencias vividas al interior de la escuela que involucran nuestro objeto de investigación que es: la evaluación en cuanto dispositivo presente en el currículo escolar de Matemática.

Entre las actividades desarrolladas en el grupo de estudio se encuentran la socialización y la reflexión de videos, lecturas, imágenes, fotografías, historietas y pruebas estandarizadas en diferentes contextos, que permiten el debate, el diálogo y la escritura narrativa.

Los encuentros individuales y grupales nos han permitido iniciar el trazado de una cartografía desde tres experiencias al interior de Instituciones 
Educativas Rurales. La cartografía, como una actitud metódica para investigar, trae la idea de "trazado de mapas" de la geografía, pero va más allá de un calcado. Deleuze \& Guattari (2004), conciben este trazado, no como un producto cerrado o calcado, sino, como un proceso abierto, que conecta diferentes puntos y líneas, relacionando incluso aquello que a simple vista no tendría conexión con el trazado.

Este trazado no hace referencia al calco de imágenes o segmentación de procesos jerarquizados, por el contrario, permite el diseño de procesos y la articulación de experiencias en las cuales se vivencian diferentes procesualidades que determinan cualidades y subjetividades.

El concepto de procesualidad de Pozzana y Kastrup (2015) supera la concepción de 'procesamiento' de registros y de datos usual en la investigación en educación que "evoca la concepción de conocimiento pautada en la teoría de la información, como recolección y análisis de informaciones" (POZZANA \& KASTRUP, 2015, p. 58). Así, comprendemos, entonces, la cartografía como la indagación de procesos de producción de subjetividades durante el desarrollo investigativo, ya que al entender el

[...] proceso como procesualidad, estamos en el corazón de la cartografía. Cuando se inicia una investigación cuyo objetivo es la indagación de procesos de producción de subjetividades, ya hay, en la mayoría de las veces, un proceso en curso. (POZZANA \& KASTRUP, 2015, p. 58).

Es decir, en nuestro trabajo nos hemos dispuesto a entender la cartografía desde el acompañamiento de procesos bajo la idea de procesualidad para permitirnos rastrear las emociones, vivencias, acontecimientos, hechos, experiencias, pensamientos, deseos y sentimientos, existentes en los profesores participantes del grupo de estudio, entendiendo que “[...] la procesualidad está presente en todos los momentos, en la recolección, en el análisis, en la discusión de los datos y también, como 
veremos en la escritura de los textos" (POZZANA \& KASTRUP 2015, p. 59).

Así, en esta investigación nos encontramos frente a cuerpos vibrátiles (en plural) que, en los encuentros grupales y encuentros individuales, no son más que cuerpos que vibran de diferentes maneras según el contexto, las actividades, las emociones, las vivencias, las experiencias y las subjetividades.

Son cuerpos vibrátiles: los cuerpos curiosos, fascinados, misteriosos, abismados, que hacen parte del proceso investigativo, los cuales exteriorizan realidades, lo que Rolnik (1989) a catalogado como quitar mascaras para mostrar caras auténticas, y es allí, mediante los cuerpos vibrátiles, que se descubren territorios, se trazan líneas y se forjan mapas que no son lineales, se parecen más a especies de rizomas.

Los cuerpos vibrátiles observan, pero no solo con el ojo orgánico, sino apoyándose en las emociones, las sensaciones y el deseo que les producen los eventos ocurridos en un espacio investigativo, provocando movimientos sutiles, los cuales no son captados por ojos de los presentes, pero si, por los cuerpos existentes, mediante los gestos, los ruidos, las expresiones, los sonidos, los actos, los silencios y los dramas, que logran generar que la piel, el pensamiento y la experiencia se exciten, así "[...] lo que nuestro cuerpo vibrátil nos hace descubrir es que el pleno funcionamiento del deseo es una verdadera fabricación incansable del mundo, es decir, lo contrario a un caos" (ROLNIK, 1989, p. 40).

Los investigadores y los profesores participantes vibran de acuerdo a las actividades propuestas, las expresiones verbales, los gestos y los hechos que ocurren en cada uno de los encuentros - individuales o grupales -, permitiendo en el transcurso de esta investigación, explorar el contexto, las experiencias de los profesores participantes y de los propios investigadores a partir del objeto de estudio, fortaleciendo la cartografía como un acompañar de procesos y no simplemente como un método predefinido.

En la perspectiva de Deleuze \& Guattari (2004) la cartografía no contiene un punto fijo o una estructura jerarquizada, debido a que su 
pensamiento se va constituyendo en el camino, las experiencias van entretejiendo sus líneas las cuales no tienen un número determinado, sino que, de acuerdo con la relación de unas con otras se van formando y van creando conexiones y redes de sentidos.

\section{[Entre] fotografías: algunos elementos para la composición de la cartografía}

En el desarrollo de uno de los encuentros grupales, en una de las Instituciones Educativas Rurales, nos dispusimos a observar unas fotografías propias del contexto, las cuales fueron capturadas entre el año 2015 y 2019. Algunas fotografías fueron colgadas de una cuerda al interior del aula de clase donde realizamos las reuniones del grupo de estudio semana a semana, y otras, fueron pegadas sobre una de las mesas (ver figura 2).

FIGURA 2: algunas fotografías dispuestas para el encuentro

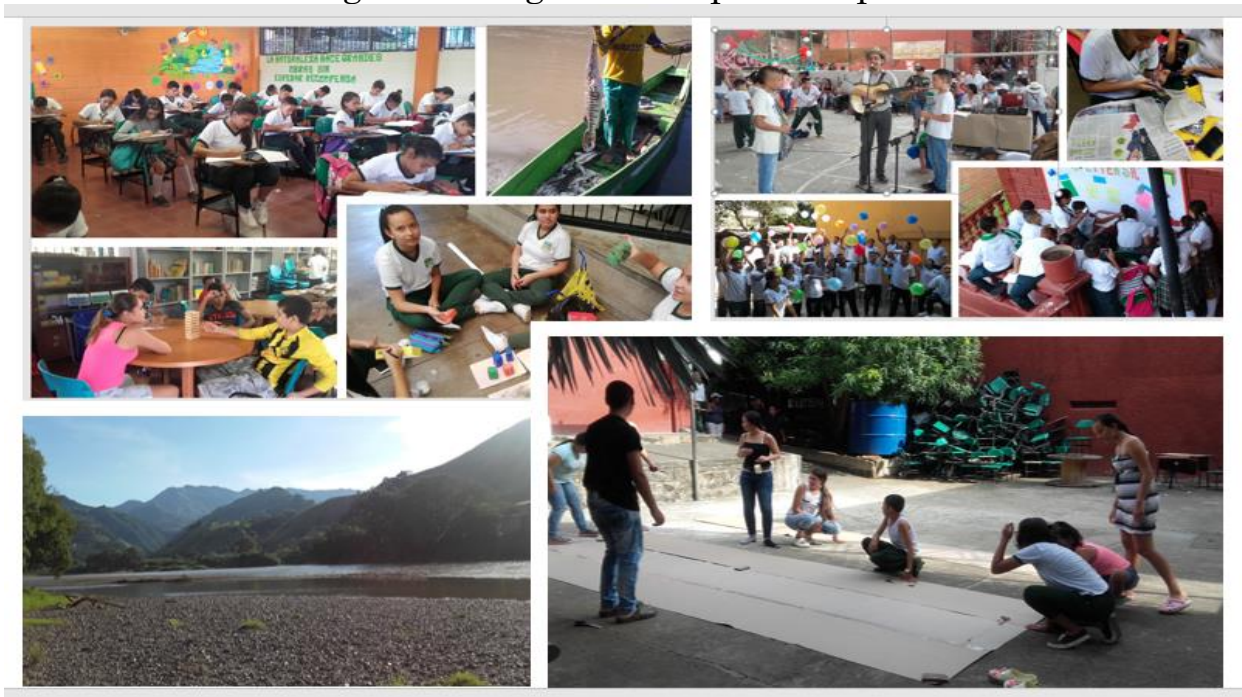

Fuente: elaboración propia de los investigadores (2019).

Los profesores al observar dichas fotografías enunciaron frases como: "es nuestra realidad", "es lo que vivimos día a día" y "es diferente estar allá que ver las fotos de lo que hacemos". Dichas expresiones nos ponen a reflexionar y analizar sobre aquello que se piensa qué es a la Educación Rural, 
la evaluación y el currículo escolar de Matemática.

Luego de una primera mirada a las fotografías, se observó a los profesores inquietos, analizando en ellas los rostros, las acciones, los momentos, las circunstancias y los espacios. Un aspecto muy interesante fue ver cómo se sentían al observar las fotografías que parecían, desde su mirada, 'capturar la realidad' de lo qué es el sistema educativo, y cómo los estados de ánimo de quienes están en ellas cambian de acuerdo con los espacios y actividades.

$\mathrm{Al}$ interactuar con las imágenes fotográficas se formaron dos grupos de profesores que seleccionaron varias imágenes para componer un mosaico con ellas. La selección de las imágenes fue libre y ellos se valieron de sus sentimientos y sensaciones para escogerlas. Cada grupo fue juntando las imágenes y pegándolas en un pliego de papel bond construyendo un mosaico. Además, a cada foto le correspondía una palabra o frase, vinculada a la sensación que ella les producía. Al final se construyeron dos mosaicos titulados "Contrastes de la evaluación” y “ipartes de?” (como podrá verse en las figuras 5 y 6 ).

Algunos profesores escogieron las fotografías haciendo comparaciones entre lo que se hace en el día a día entorno a la evaluación y lo que se quiere o se sueña. En ese proceso de selección de las imágenes fotográficas, una de las profesoras toma dos fotografías, sujeta una en cada mano y le dice a los demás: "hasta el rostro de los chicos cambia. Cuando están en filas y encerrados en el aula de clase se ven aburridos nuestros chicos (ver figura 3). $Y$, cuando están en un pasillo aprendiendo entre ellos y compartiendo lo que piensan se ven alegres (ver figura 4)". Ella prosigue: "observen la disposición en el aula y la disposición en otros lugares donde también se aprende; también se puede evaluar". 
FIGURA 3: Fotografía de una práctica evaluativa (examen)

Fuente: elaboración propia de los investigadores (2016).

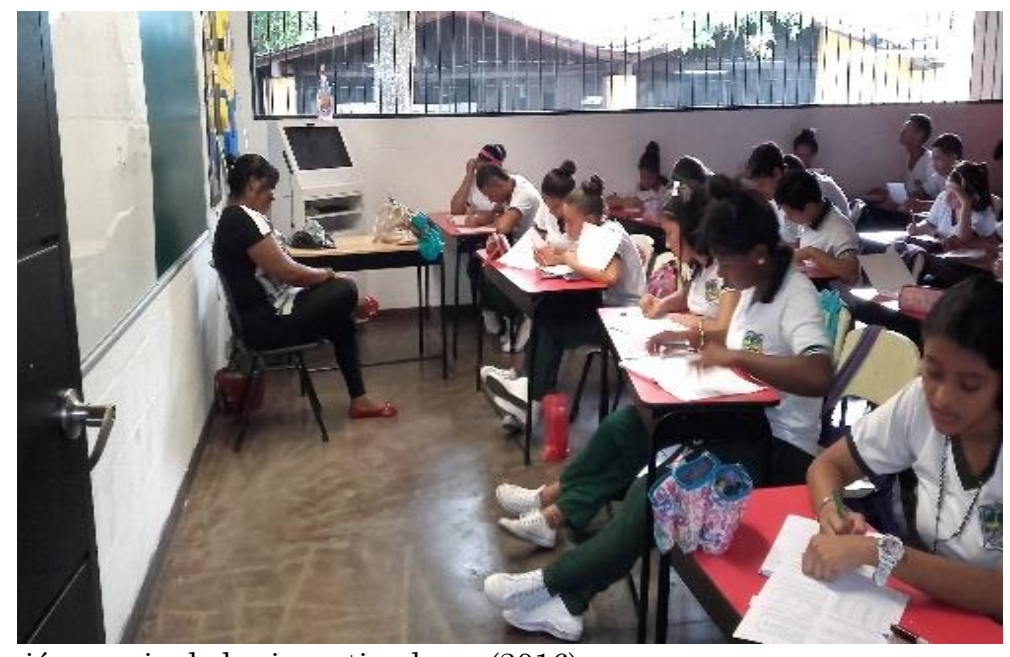

FIGURA 4: Fotografía de una práctica evaluativa (trabajo en equipo).

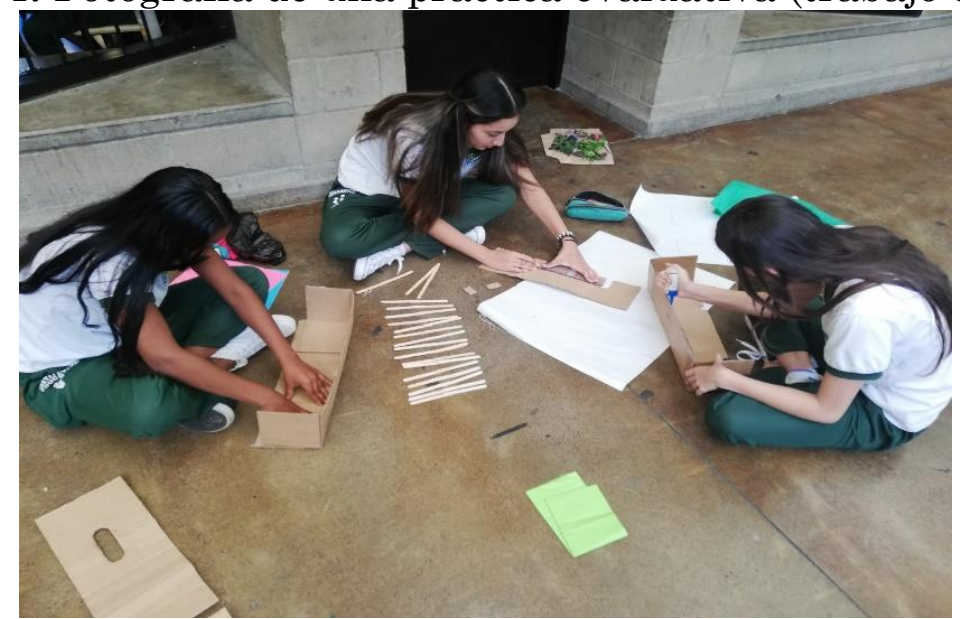

Fuente: elaboración propia de los investigadores (2018).

Los mosaicos fueron realizados entre rizas e indignaciones por la forma en cómo se viven en la escuela las prácticas examinadoras, las formas de disciplinarización del cuerpo que involucran un aprender como re-cognición ${ }^{17}$. Al terminar la elaboración de los mosaicos, nos dispusimos a compartir y reflexionar sobre lo elaborado destacando qué fue lo que se tuvo en cuenta para su elaboración.

El primer grupo de profesores argumentó que se dedicó a observar ¿cómo se evalúa en las aulas de clase? y ¿cómo se puede transformar esa

${ }^{17}$ GALLO, 2012. 
evaluación en algo más dinámico?, es por ello que el título de su mosaico fue “contrastes de la evaluación” (ver figura 5) buscando manifestar que, en las aulas de Matemática, existen metodologías de enseñanza estandarizadas, se espera que los niños aprendan de la misma forma, existen formas de vigilancia y carencia de nuevas concepciones de enseñanza, lo que impide que la práctica pedagógica se realice de una forma creativa y apropiada al contexto.

El primer mosaico nos puso a reflexionar sobre la evaluación basada en juegos, en aprendizajes colaborativos, en las realidades del contexto y bajo una participación de todos los involucrados, pero al mismo tiempo comenzamos a preguntarnos ¿será que esto no examina de la misma forma que una prueba escrita?

FIGURA 5: Mosaico "Contrastes de la evaluación”

Fuente: elaboración propia de los investigadores (2019).

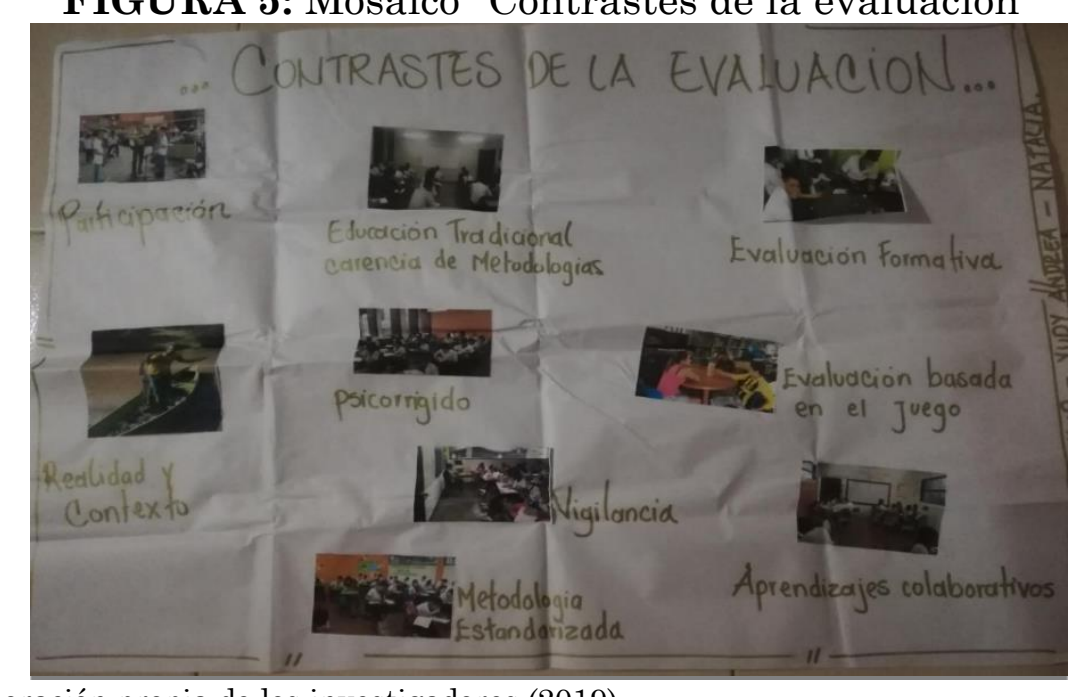

El segundo grupo de profesores dijo que se había fijado en la realidad contextual, en las dinámicas propias de los estudiantes y sus relaciones con la institución y entorno, así el título a su mosaico (ver figura 6) fue: “ipartes de?”, manifestando que el contexto, la participación, la indagación, el trabajo colaborativo, las manifestaciones del ser, intercambio y espacios, hacen parte de esas otras miradas que hay que tener en cuenta para pensar la evaluación 
más allá de las disciplinas.

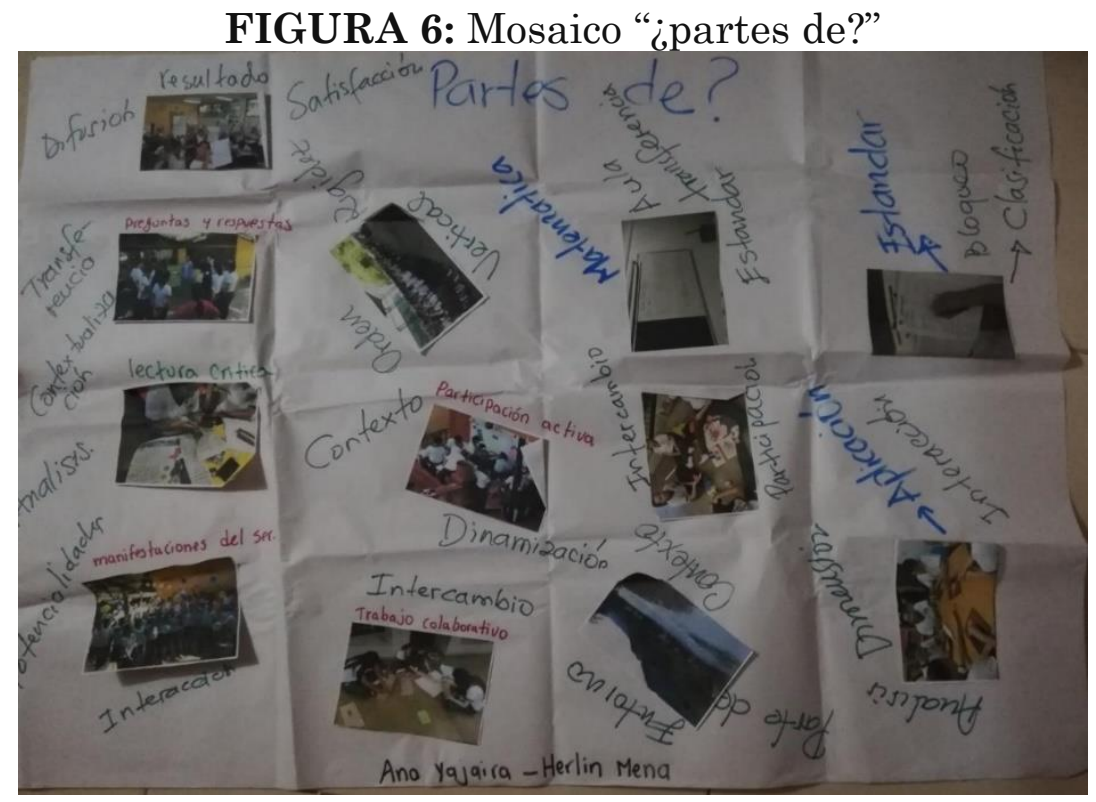

Fuente: elaboración propia de los investigadores (2019).

Con esta experiencia comenzamos a observar que los profesores poseen diferentes concepciones de evaluación, vinculadas a sus experiencias como estudiantes y, ahora como profesores de contexto rural. Dentro de sus discursos percibimos que se manifiesta una concepción de evaluación como un dispositivo que crea cuerpos dóciles, sin embargo, al cuestionarla abren brechas para crear alternativas desde un currículo escolar de Matemática centrado en el sujeto rural desde sus historias, realidades y culturas.

$\mathrm{Y}$, es justamente, esta investigación la se espera nos ayude abrir margen para prácticas evaluativas otras que permitan hacer de la educación un proceso de constante reflexión sobre el mundo rural y la vida que en él se realiza, y que nos permita crear brechas para superar desde el aula de Matemática la concepción de una escuela que examina, excluye y disciplinariza los cuerpos y el saber.

\section{Comentarios Finales del Proceso Investigativo}

Aunque esta investigación aún no ha finalizado, hemos aprendido en el 
trabajo de campo que cada institución tiene sus problemas y particularidades curriculares, que la ruralidad y con ello la escuela rural, no son homogéneas y, desde allí, vemos que, la cartografía, nos permitirá dar voz a lo singular de cada contexto para trazar posibilidades de resistencia y revuelta que transgredan las políticas de evaluación estandarizas que permean la vida en la escuela rural, lo que nos acercará por diferentes vías de interpretación a respuestas para nuestra pegunta de investigación.

Gracias a las voces de los profesores, y la experiencia vivida en esta actividad pudimos ver la necesidad que ellos tienen de problematizar la evaluación a partir de nosotros mismos dando atención a la vida que vivimos en la escuela rural. Tal problematización, esperamos, nos permita no solo desterritorializar la evaluación como dispositivo de control presente en el currículo de Matemática, sino, que también, nos permita (re)significarla, colocándola en tela de juicio como actividad punitiva y sistémica.

En este proceso hemos venido aprendiendo que una de las preguntas fundamentales a ser discutidas en cuanto investigadores es żcómo operacionalizamos la evaluación en los discursos escolares dentro del currículo de Matemática? y, no ¿qué es la evaluación? y, de esta manera junto a los profesores, pensar la evaluación como dispositivo desde la particularidad de las escuelas rurales, aprendiendo desde la práctica educativa. La pregunta por el "como" nos coloca en el plano de vida para que, el aula de clase de Matemática sea el lugar donde se encuentran diferentes culturas y cosmogonías, las cuales permitan ver la evaluación como un proceso constante, reflexivo y propositivo, y no como la ejecución de prácticas examinarías en pro del mantenimiento de redes de poder/saber que excluyen a los sujetos y clasifican sus experiencias.

\section{Referências}

ABÓS, P. \& BOIX, T. Evaluación de los aprendizajes en escuelas rurales multigrado. Aula Abierta, España, N. 45, p. 41-48, septiembre/diciembre.2017. Disponible en: https://dialnet.unirioja.es/servlet/articulo?codigo $=6060639$. 
AGAMBEN, G. ¿Qué es un dispositivo? Sociología. (Traducido por Fuentes, R.). v. 26 , N. $73, \quad$ p. 249-269, mayo/agosto. 2011. Disponible en http://www.scielo.org.mx/scielo.php?script=sci arttext\&pid=S018701732011000200 $\underline{010}$.

AMARIS, P. Bases da cartografia em termos de Foucault/Deleuze na Educação Matemática. Anais do XI Encontro Nacional de Educação Matemática. Curitiba. 2013. Disponible en: https://docplayer.com.br/18310463-Bases-da-cartografia-emtermos-de-foucault-deleuze-na-educacao-matematica.html .

AMORIM, S. Uma ideia de cartografia. 2010. Tesis de Maestría-Universidade Estadual de Campinas, Brasil.

ARIAS, J. Problemas y retos de la educación rural colombiana. Educación y Ciudad. N. 33 , p. 53-62, junio/diciembre. 2017. Disponible en: https://dialnet.unirioja.es/servlet/articulo?codigo $=6213576$

BOIX, T. La escuela rural en la dimensión territorial. Innovación educativa. N. 24, p. 89-97, agosto/octubre. 2014. Disponible en: http://www.usc.es/revistas/index.php/ie/article/view/1959 .

BOIX, T. ¿Qué queda de la escuela rural? algunas reflexiones sobre la realidad pedagógica del aula multigrado. Revista de currículum y formación del profesorado. v. $15, \quad \mathrm{~N} . \quad 2$, p. 13-23, julio. 2011. Disponible en: https://www.redalyc.org/articulo.oa?id=56719129002.

BOIX, T. Escuela rural y territorio: entre la desruralización y la cultura loca. Revista Digital e Rural, Educación, cultura y desarrollo rural. v. 1, N. 1, p. 1-8. (2003). Disponible en: http://educación.upa.cl/revistaerural/erural.htm .

CLARETO, S. Matemática como acontecimento na sala de aula. $36^{\circ}$ Reunião nacional de ANPEd. Goiãnia-Go. $2013 . \quad$ Disponible en: http://36reuniao.anped.org.br/pdfs trabalhos aprovados/gt19 trabalhos pdfs/gt19 3248 texto.pdf.

DELEUZE, G. \& GUATTARI, F. Mil mesetas: capitalismo y esquizofrenia. (Traducido de Vázquez, J.). España: PRE-TEXTOS, 2004.

FOUCAULT, M. Vigilar y Castigar: El nacimiento de la prisión. (Traducido de Garzón, A.). México: Siglo XXI Editores, 2009.

FOUCAULT, M. Estética, ética y hermenéutica. (Traducción de Gabilondo, Á.). Barcelona: Editorial Paidós, 1999.

FOUCAULT, M. Las palabras y las cosas: una arqueología de las ciencias humanas. (Traducción de Frost, E). Argentina: Siglo XXI Editores, 1968.

GALLO, S. As Múltiplas Dimensões do Aprender. Congreso de educação Básica: Aprendizagem e Currículo. Congresso dirigido por COEB, Brasil. 2012. Disponible 
en:

http://www.pmf.sc.gov.br/arquivos/arquivos/pdf/13_02_2012_10.54.50.a0ac3b8a140 676ef8ae0dbf32e662762.pdf.

GLAVAM, C. \& SOAREZ, J. Educação do campo e educação matemática: possíveis entrelaçamentos. Revista Reflexão e Ação, Santa Cruz do Sul, v. 25, N. 1, p. 80-98, enero/abril. $2017 . \quad$ Disponible en: https://online.unisc.br/seer/index.php/reflex/article/view/5098.

JARAMILLO, D. La educación matemática en una perspectiva sociocultural: tensiones, utopías, futuros posibles. Revista Educación y Pedagogía, Colombia, v. 23, N. 59, p. 13-36, enero/abril. 2011. Disponible en: http://aprendeenlinea.udea.edu.co/revistas/index.php/revistaeyp/article/view/8688 .

KNIJNIK, G. Etnomatemáticas en movimiento: perspectiva etnomatemática, sus formulaciones y teóricas y ejemplificaciones. Revista Latinoamericana de Etnomatemática, San Juan de Pasto, v. 7, N. 2, p. 119-131, junio. 2014. Disponible en: http://www.etnomatematica.org/ojs310/index.php/RevLatEm/article/view/127 .

LIZCANO, E. Las matemáticas de la tribu europea: Un estudio de caso. II International Congress on Ethnomathematics, Ouro Preto, Brasil, 5 de agosto. 2002. Disponible en: http://www.unavarra.es/puresoc/pdfs/c salaconfe/0-Lizcano-03-1.pdf.

MONTEIRO, A \& MENDES, J. Prácticas sociales y organización curricular: cuestiones y desafíos. Revista Educación y pedagogía, Colombia, v. 23, N. 59, p. 3746, enero/abril. 2011 Disponible en: http://aprendeenlinea.udea.edu.co/revistas/index.php/revistaeyp/article/viewFile/86 $\underline{90 / 8004}$.

MORAL, M. Poder disciplinario y educación: aproximación foucaultiana desde la Psicología Social. En Athenea Digital, v. X, N. 13, p. 71-94, primavera. 2008. Disponible en: https://atheneadigital.net/article/view/n13-moral .

MORALES, A. \& VEIGA-NETO, A. Disciplina e controle na escola: do aluno dócil ao aluno flexível. IV Colóquio Luso-Brasileiro sobre questões curriculares. UFSC, Florianópolis, Brasil. 2008.

NÚÑEZ, J. Saberes y educación: una mirada desde las culturas rurales. Revista digital, cultura y desarrollo rural. v. 1, N. 2, p. 1-8, enero. 2004. Disponible en: http://educación.upa.cl/revistaerural/erural.htm .

PASSOS, E., KASTRUP, V. \& ESCÓSSIA, L. Pistas do método da cartografia: pesquisa-intervenção e produção de subjetividade. Porto Alegre: Editora Meridional LTDA, 2015.

POZZANA, L. \& KASTRUP, V. Cartografar é acompanhar processos. En PASSOS, V. KASTRUP \& L. ESCÓSSIA (Ed.), Pistas do método da cartografia: pesquisaintervenção e produção de subjetividade. Porto Alegre: Editora Meridional LTDA, 2015. 
QUICENO, H. \& PENAALOZA, M. El dispositivo de la evaluación: cartografía de la producción de conocimiento en el campo de la evaluación en Colombia. Pedagogía y Saberes, Bogotá, N. 41, p. 45-61, septiembre/octubre. 2014. Disponible en: http://revistas.pedagogica.edu.co/index.php/PYS/article/view/3312 .

QUIROGA, R. Escuela y producción de subjetividad. El papel de la educación en la sociedades del gerenciamiento y el paradigma de la gestión escolar. IXTLI. En Revista Latinoamericana de Filosofía de la Educación, Santiago de Chile, v. 4, N. 8, p. 221-235, 2017.2 Disponible en: http://ixtli.org/revista/index.php/ixtli/article/view/86 .

RESENDE, H. Sociedade avaliativa: o exame como mecanismo de controle e gestão populacional. En CARVALLHO, A. \& GALLO, S. Repensar a educação: 40 anos após Vigiar e Punir. Brasil: Editora Livraria da Física, 2015.

ROLNIK, S. Cartografia sentimental: transformações contemporâneas do desejo. São Paulo: Estação Liberdade, 1989.

SÁNCHEZ-AMAYA, T. La evaluación educativa como dispositivo de constitución de sujetos. Revista Latinoamericana de Ciencias Sociales, Niñez y Juventud, Bogotá, v. $11, \quad$ N. 2, p. 755-767, agosto/octubre. 2013. Disponible en: http://www.scielo.org.co/pdf/rlcs/v11n2/v11n2a21.pdf .

SÁNCHEZ-AMAYA, T. Aproximación a un estudio genealógico de la evaluación en Colombia, siglo XX. Revista Latinoamericana de Ciencias Sociales, Niñez y Juventud, Bogotá, v. 7, N. 2, p. 1675-1711, abril. 2009. Disponible en: https://repository.cinde.org.co/handle/20.500.11907/532 .

SILVA, T. El proyecto educacional moderno ¿identidad terminal? Revista propuesta educativa, N. 13, p. 1-9, 1995. Disponible en: http://www.terras.edu.ar/biblioteca/5/PDGA_Da_Silva_Unidad_7.pdf .

SILVA, T. Documentos de identidad: una introducción a la teoría del currículo. Belo Horizonte: Aautêntica Editorial, 1999.

TAMAYO-OSORIO, C. Currículo escolar, conocimiento [matemático] y prácticas sociales: posibilidades otras en una comunidad indígena Gunadule. Educ. Pesqui, São Paulo, v. 42, N. 4, p. 903-919. out./dez. 2016. Disponible en: http://www.scielo.br/pdf/ep/v42n4/1517-9702-ep-42-04-0903.pdf .

VALENCIA, L. Estereotipos y educación rural: visibilizando los hilos que tejen el sentido de la educación en el campo. Estudio de caso etnográfico en una institución educativa rural del municipio de marinilla. 2015. Tesis de Maestría-Universidad De Antioquia, Medellín.

VEIGA-NETO, A. Biopolítica, normalización y educación. Pedagogía y Saberes, Bogotá, N. 38, p. 83-91, $2003 . \quad$ Disponible en: http://revistas.pedagogica.edu.co/index.php/PYS/article/view/2141 .

VEIGA-NETO, A. Crise da modernidade e inovações curriculares: da disciplina para 
o controle. Trajetórias e processos de ensinar e aprender: sujeitos, currículos e culturas. Memorias del XIV ENDIPE, p. 35-58, 2008. Disponible en: http://www.grupodec.net.br/wpcontent/uploads/2015/10/CrisedaModernidadeAlfred o.pdf.

VEYNE, P. Foucault. Pensamiento y vida. (Traducido por Furió, M.). Barcelona, España: Ediciones Paidós Ibérica, S.A., 2008.

WALKER, A. \& TAMAYO-OSORIO, C. Evaluaciones estandarizadas, modelos de aculturación y transgresión en las comunidades indígenas colombianas. Zetetiké, Campinas, v. 26, N. 1, p. 21-40, enero/abril. 2018. Disponible en: https://periodicos.sbu.unicamp.br/ojs/index.php/zetetike/article/view/8650888 .

ZANLORENZI, M. Relações de Poder e Educação Matemática: do poder disciplinar à possibilidade de resistências. Perspectivas da Educação Matemática INMA/UFMS, v. 10, N. 22, p. 284-305, 2017. Disponible en: http://seer.ufms.br/index.php/pedmat/article/view/3199.

Recebido em novembro de 2019.

Aprovado em janeiro de 2020. 